\title{
Microbiological Control of Internal Surfaces of Appliances in the Butcher's Cold Chain in Lubumbashi
}

\author{
Chadrack Kabeya Diyoka1*, Isabelle Kasongo Omba1,2, Ghyslain Ngongo Lambo, ${ }^{1,2}$, \\ Eric Kasamba Ilunga ${ }^{3}$, Prosper Emmanuel Malangu Mposhy,4, Criss Koba Mjumbe1,2 \\ ${ }^{1}$ School of Public Health, University of Lubumbashi, Lubumbashi, DR Congo \\ ${ }^{2}$ Department of Public Health, University of Lubumbashi, Lubumbashi, DR Congo \\ ${ }^{3}$ Department of Biomedical Sciences, Faculty of Medicine, University of Lubumbashi, Lubumbashi, DR Congo \\ ${ }^{4}$ Faculty of Veterinary Medicine, University of Lubumbashi, DR Congo \\ Email: *ckdgroupe02@gmail.com
}

How to cite this paper: Diyoka, C.K., Omba, I.K., Lambo, G.N., Ilunga, E.K., Mposhy, P.E.M. and Mjumbe, C.K. (2021) Microbiological Control of Internal Surfaces of Appliances in the Butcher's Cold Chain in Lubumbashi. Open Access Library Journal, 8: e7731. https://doi.org/10.4236/oalib.1107731

Received: July 5, 2021

Accepted: August 8, 2021

Published: August 11, 2021

Copyright $\odot 2021$ by author(s) and Open Access Library Inc.

This work is licensed under the Creative Commons Attribution International License (CC BY 4.0).

http://creativecommons.org/licenses/by/4.0/

\begin{abstract}
Introduction: Food contamination with microorganisms can occur at any stage of the process, from food production to consumption, and can be the result of environmental contamination. This study was carried out in order to identify the microorganisms forming the flora and to determine the level of microbial contamination of the internal surfaces of devices in the cold chain of butcher shops. Method: This is a comparative cross-sectional descriptive study of 30 internal surfaces of ten devices in the chain of two butchers. Results: It seems that the sampling points of Butchery 1 have the highest level of contamination at $87 \%$ compared to Butchery $2(46.67 \%)$ with a $\mathrm{p}=0.02508(<0.05)$. the organisms isolated were $S$. aureus (54\%) and albus (23\%), fusarium and A. niger respectively with $8 \%$, and $A$. fumagitus (7\%); against $47 \%$ (Boucherie II) with a, The isolated microorganisms were $S$. aureus (43\%), 29\% for K. planticola and $14 \%$ for A. fumagitus and fusarium spp. The level of surface contamination for all isolated organisms was $>1000 \mathrm{CFU} / \mathrm{cm}^{2}$. The operating temperature range of the devices varied between $-2^{\circ} \mathrm{C}$ and $6^{\circ} \mathrm{C}$, with an average of $-3.2^{\circ} \mathrm{C}$ in Butchery 1 versus $-4.6^{\circ} \mathrm{C}$ and $6^{\circ} \mathrm{C}$, with an average of $-4^{\circ} \mathrm{C}, 7^{\circ} \mathrm{C}$ for the Butcher

2. Conclusion: Food pathogens and opportunists can survive on the surfaces of cold chain equipment in butcher shops and therefore pose a risk of crosscontamination.
\end{abstract}

\section{Subject Areas}

Microbiology 


\section{Keywords}

Control, Microbial Contamination, Internal Surfaces, Cold Chain Devices

\section{Introduction}

Cross-contamination of food with pathogens in the retail environment is a significant public health problem that contributes to an increased risk of foodborne illness [1]. The World Health Organization estimates that 1800 million episodes of diarrhea and 3 million deaths of children under 5 occur each year worldwide, mainly due to contaminated food. Foodborne pathogens cause both acute and chronic illnesses [2]. Food contamination with microorganisms can occur at any stage of the process, from food production to consumption, and can be the result of environmental contamination.

The internal faces of cold chain devices can be contaminated by pathogenic microorganisms of food origin [3]. Although the low temperature delays food spoilage, but even sub-freezing at a temperature of around $7^{\circ} \mathrm{C}$ does not prevent the multiplication of all microorganisms, therefore refrigerated food is subject to spoilage by molds, yeasts and bacteria.

Existing global food safety standards help improve and standardize manufacturing practices, good hygienic practices, risk analysis, critical control point, for safer processed foods [4], are not necessarily implemented in the food industry around the world. In addition, there is insufficient information regarding the assessment of food safety practices, foodborne illnesses and the microbial load on food contact surfaces, including internal surfaces of appliances. The butcher's cold chain is on a regular basis.

Hence the interest to deepen the knowledge on the current state of butchers, includes bacteriological analysis of food samples and environmental risk assessment and training of staff, in order to improve the quality microbiological of internal surfaces of cold chain devices. We therefore sought to identify the microorganisms forming the flora and to determine the level of microbial contamination of the internal surfaces of devices in the cold chain of butcher shops.

\section{Methodology}

We carried out a comparative cross-sectional descriptive study in two butchers in the city of Lubumbashi. Haut-Katanga province in the Democratic Republic of Congo (DRC) is over a period from June 29 to July 11, 2020, i.e. two weeks. Thirty (30) samples were taken from the internal surfaces of 10 devices in the cold chain of butcher shops accessible with the consent of the promoter. The sample was taken under aseptic conditions. Samples were taken from the bottom and from two surfaces using the dry sterile swabs and sent to the laboratory for analysis within one hour of collection. Different culture media were prepared according to the recommendations of the manufacturers. To obtain the isolated bacte- 
ria the samples were inoculated on CLED Agar, mannitol salt agar and Mac Conkey Agar. Microbiological analysis: To obtain the fungal isolates, the samples were inoculated on Sabouraud Dextrose Agar (SDA). The initial identification of the isolated bacteria was based on their cultural and morphological characteristics. Further identification was by biochemical characteristics using standard procedures. GRAM coloring: A thin smear from a 24-hour culture was made on a fat-free, heat-fixed slide by passing the slide quickly over a Bunsen burner flame after air drying. The prepared smear was then flooded with crystal violet solution for about one minute, rinse with tap water; followed by mordanting with Lugol (iodine-iodine solution): spread the Lugol and leave to act for 1 minute, rinse with tap water; after $\mathrm{d}$ colorless with alcohol (+acetone): pour the alcohol or an alcohol-acetone mixture drop by drop onto the slanted slide, and monitor the discoloration (30 seconds). Rinse with tap water; the smear was counterstained with Safranin for 1 minute, washed with tap water; Air dry the slide; Observe with a drop of objective $100(\times 1000)$ immersion oil. Color purple signifies a gram positive organism while pink to red signifies gram negative. Catalase test: Place on a glass slide one or two drops of hydrogen peroxide at 10 volumes. Using the taper of a Pasteur pipette, take a fragment of a colony and dissociate the culture in hydrogen peroxide. The release of bubbles immediately indicated a positive test while it was negative when no bubbles were formed.

\section{Interpretations}

Statistical analysis: The microbiological results obtained after incubation were entered using MS Excel 2016 software; processed and analyzed with Excel 2016 and Epi info software version 7.2.2.6. For the analysis and interpretation of the data, the following calculations and statistical tests were used: frequency, mean and standard deviation, the Fischer Exact test and the Mann-Whitney/Wilcoxon test.

\section{Results}

After the text edit has been completed, the paper is ready for the template. Duplicate the template file by using the Save As command, and use the naming convention prescribed by your journal for the name of your paper. In this newly created file, highlight all of the contents and import your prepared text file. You are now ready to style your paper.

\subsection{Level of Contamination of Surfaces and Isolated Microorganisms}

Table 1 shows that the points of sampling butchery 1 have a highest contamination level to $87 \%$ relative compared to the butchery 2 which has a frequency of $46.67 \%$ of contaminated areas. There is a significant difference between the contamination of the internal surfaces of the cold chain devices between butchery I and II $0.02508(<0.05)$. Concerning the microorganisms isolated from the internal surfaces of the cold chain devices, we observed a predominance of bacteria at $75 \%$, and molds were in second position at $25 \%$. The bacterial contamination and 
fungal were respectively distributed in the following manner depending on whether the slaughter 1 and 2: 77\% and 23\% against 71\% and 29\% (Table 2). The distribution of bacteria and molds is greater than $1000 \mathrm{CFU} / \mathrm{cm}^{2}$ or $1 \log _{10} \mathrm{CFU} / \mathrm{cm}^{2}$ on all surfaces sampled. The level of hygiene/cleaning of the internal surfaces of refrigerators and refrigerated cabinets was respectively unacceptable and distributed as follows depending on whether it was butchery 1 and 2: 89\% and 33\% against $83 \%$ and $56 \%$ (because $>1 \log _{10} \mathrm{CFU} / \mathrm{cm}^{2}$ ), and require effective cleaning/disinfection. In terms of percentage (Table 3), Staphylococcus aureus represent $54 \%$ of the germs counted and against $7 \%$ of Aspergillus fumigatus. (Butcher I) and Staphylococcus aureus represent $43 \%$ of the counted flora, Klebsiella planticola (29\%) and 14\% respectively for Aspergillus fumagitus and Fusarium spp. The average counts of the microorganisms detected on the internal surfaces of the cold chain devices are presented in Table 4, as follows depending on whether

Table 1. Distribution of the overall contamination of surfaces by cleaning assessment.

\begin{tabular}{rcccc}
\hline & \multicolumn{4}{c}{ Contamination of surfaces } \\
\cline { 2 - 5 } Structure & \multicolumn{3}{c}{ No } & \multicolumn{2}{c}{ Yes } \\
\cline { 2 - 5 } & Frequency & Percentage (\%) & Frequency & Percentage (\%) \\
\hline Butcher I & 2 & 20 & 13 & 87 \\
Butcher II & 8 & 53 & 7 & 47 \\
\hline
\end{tabular}

${ }^{*} \mathrm{p}=0.02508$.

Table 2. Distribution of microorganisms isolated from internal surfaces of cold chain devices.

\begin{tabular}{ccccc}
\hline \multirow{2}{*}{$\begin{array}{c}\text { Isolated } \\
\text { microorganisms }\end{array}$} & \multicolumn{2}{c}{ Butcher I } & \multicolumn{2}{c}{ Butcher II } \\
\cline { 2 - 5 } & Frequency & Percentage (\%) & Frequency & Percentage (\%) \\
\hline Bacteria & 10 & 77 & 5 & 71 \\
Molds & 3 & 23 & 2 & 29
\end{tabular}

Table 3. Global distribution of microbial strains isolated from internal surfaces of cold chain devices.

\begin{tabular}{ccc}
\hline \multirow{2}{*}{ Isolated microorganisms } & \multicolumn{2}{c}{ Percentage (\%) } \\
\cline { 2 - 3 } & Butcher I & Butcher II \\
\hline Staphylococcus & 54 & 43 \\
Staphylococcus aureus & 23 & 0 \\
Staphylococcus albus & 0 & 29 \\
Klebsiella planticolla & & \\
Molds & 7 & 14 \\
Aspergillus fumagitus & 8 & 0 \\
Aspergillus niger & 8 & 14 \\
Fusarium spp. & &
\end{tabular}


Table 4. The average of the microbiological analyzes compared to the sampling points.

\begin{tabular}{ccc}
\hline \multirow{2}{*}{ Flora } & \multicolumn{2}{c}{ Average \pm Etype } \\
\cline { 2 - 3 } & Butcher I & Butcher II \\
\hline Staphylococcus & $3.47 \pm 0.5$ & $0.80 \pm 2.21$ \\
Klebsiella planticolla & - & $0.51 \pm 1.57$ \\
Fusarium spp. & $0.27 \pm 1.04$ & $0.26 \pm 0.97$ \\
Aspergillus & $0.53 \pm 1.68$ & $0.27 \pm 1.04$ \\
\hline
\end{tabular}

${ }^{*} \mathrm{p}=0.7490$.

it was butchery 1 st 2 (in $\left.\log 10 \mathrm{CFU} / \mathrm{cm}^{2}\right)$ : S. aureus and albus 3.47 and 0.80 , aspergillus fumagitus and niger 0.53 and 0.27 for fumagitus; fusarium 0.27 and 0.26 . Klebsiella planticola 0.51 . The difference between the averages of microbial contamination of the internal surfaces of devices in the cold chain of butcheries is not significant. With a $\mathrm{p}=0.7490(>0.05)$.

\subsection{Operating Temperature of Cold Chain Devices}

The temperature of the devices of the observed Butcher I ranged from $-2^{\circ} \mathrm{C}$ to $6^{\circ} \mathrm{C}$, with an average temperature of $-3.2^{\circ} \mathrm{C}$. The temperature ranges of the cold chain devices observed (Butcher 2) varied between $-4.6^{\circ} \mathrm{C}$ and $6^{\circ} \mathrm{C}$, with an average temperature of $-4.7^{\circ} \mathrm{C}$.

\subsection{Cleaning/Disinfection Procedure}

The answers of the people questioned reveal that the cleaning of the internal surfaces of the cold chain devices is carried out every morning before the start of activities and the opening for the sale of food in the two butcheries, and at the end of each. Day to restore the surfaces to a clean state in the butcher's shop I; The sponge (cloths), squeegee and buckets are the cleaning tools most often used in both structures. The cleaning/disinfection products used contained acetic acid and bleach as active ingredients.

\section{Discussion}

\subsection{Surface Contamination Level}

The sampling points of Butchery 1 have the highest level of contamination at $87 \%$ compared to Butchery 2 which has a frequency of $46.67 \%$ of contaminated areas. There is a significant difference between the contamination of the internal surfaces of the cold chain devices between butchery I and II $0.02508(<0.05)$. OtuBassey et al., 2017 found that $100 \%$ of refrigerators inspected show bacterial contamination, $32 \%$ fungal contamination and $8 \%$ contamination by parasitic organisms.

According to the indications of the service note DGAL/SDSSA/N2007-8275 France on the microbiological criteria applicable to carcasses of slaughter animals and poultry, and of the guidelines relating to the surface controls of the material 
in slaughterhouses and in cutting plants slaughter animals and poultry. Our results are unsatisfactory because they are greater $1000 \mathrm{CFU} / \mathrm{cm}^{2}$ or $1 \log _{10} \mathrm{CFU} /$ $\mathrm{cm}^{2}$ on all surfaces sampled [5]. The level of hygiene/cleaning the internal surfaces of refrigerators and refrigerated cabinets was not acceptable, respectively, and distributed as follows depending on whether it was the slaughter 1 and 2: 89\% et $33 \%$ against $83 \%$ et $56 \%$, and require effective cleaning/disinfection. This result is similar ith one of Zickrick K. et al., who found that $17.2 \%$ of domestic refrigerators in Germany contained $>1000 \mathrm{CFU} / \mathrm{m}^{3}$ [6]. And are not consistent with those found by Altunatmaz et al. who found psychrotrophic bacteria in all air sampled to be $<200 \mathrm{CFU} / \mathrm{m}^{3}[7]$.

At the butcher I, $S$. aureus account for $54 \%$ of enumerated bacteria, followed by $S$. albus (23\%) of $A$. Niger and Fusarium spp (8\%), A. fumagitus (7\%); on the other hand, at the level of butchery II, $S$. aureus represent $43 \%$ of the counted flora, $K$. planticola (29\%) and respectively $14 \%$ for asp. fumagitus and fusarium spp. Macias-Rodriguez et al., In 2013; Kampmann et al., In 2008; Otu-Bassey et al., In 2017 reported that the bacterial genera isolated in decreasing order of frequency were: Staphylococcus aureus 27.3\%, Escherichia coli 20.2\%, Shigella spp. 13.0\%, Pseudomonas aeruginosa 11.9\%, Aeromonas hydrophilia 8.3\%, Salmonella typhi 5.9\%, Klebsiella pneumonia 5\%, Streptococcus pyogenes $4.7 \%$ and Proteus mirabilis $2.3 \%$. The fungal organisms isolated were $\mathrm{C}$ andida albicans $54 \%$, penicillium spp $43.2 \%$ and a spergilus flavus $2.7 \%$ while the parasites detected were Entamoeba histolytica/dispar 50\% and Ascaris lumbricoides 50\% [6] [7] [8].

The averages of the count of microorganisms detected on the internal surfaces of the cold chain devices are presented as follows depending on whether it was butchery 1 st 2 (in $\log _{10} \mathrm{CFU} / \mathrm{cm}^{2}$ ): Staphylococcus aureus and albus 3,47 and 0.80 , aspergillus fumagitus and niger 0.53 and 0.27 for fumagitus; fusarium 0.27 and 0.26 . Klebsiella planticola 0.51 . The difference between the averages of microbial contamination of the internal surfaces of devices in the cold chain of butcheries is not significant. With a p $=0.7490$ (>0.05). Otu-Bassey et al., In 2017; Oluwafemi et al., in 2015. Have isolated other species of bacteria and fungi in home refrigerators, Staphylococcus aureus, Escherichia coli, Bacillus subtilis, Enterobacter spp., Klebsiella spp. and Shigella spp., Aspergillus flavus, A. niger, A. fumigatus, Saccharomyces cerevisae and Rhizopus spp. [9] [10] [11].

These unwanted organisms may have entered cold chain devices from unwashed raw foods, poorly packaged foods (meats, eggs, and milk), dirty hands, through an open refrigerator door, fluctuating temperatures, and surfaces of unsuitable containers placed in the refrigerator.

\subsection{The Operating Temperature of Cold Chain Devices}

Temperature is one of the main factors in controlling food quality and safety due to its influence on microbial growth rates. Despite the fact that the low temperature can reduce the growth rate of many species of microorganisms, it has been reported that psychrotrophic microorganisms can thrive under normal refrige- 
ration temperatures [12]. For Butcher I, the temperature range varied between $-2^{\circ} \mathrm{C}$ and $6^{\circ} \mathrm{C}$, with an average temperature of $-3.2^{\circ} \mathrm{C}$. For Butcher II, the temperature range varied between $-4.6^{\circ} \mathrm{C}$ and $6^{\circ} \mathrm{C}$, with an average temperature of $-4.7^{\circ} \mathrm{C}$.

The WHO [13] recommends the temperature at which food is stored at a maximum of $5^{\circ} \mathrm{C}$ in the refrigerator [14], reported that a drop in temperature is important to retard the growth of pathogens and other microorganisms during the shelf life of the product, especially after the product is purchased and under the responsibility of producers or consumers of food.

\subsection{Cleaning/Disinfection Process}

To eliminate a maximum of microorganisms, it is advisable to carry out a cleaning with a detergent, in order to eliminate the major part of the soils present on the surfaces, then to disinfect.

The antimicrobial properties of acetic acid are attributed to their acetic acid and citric acid content, respectively [15]. It is believed that these organic acids cross the cell membrane of bacteria and that the release of protons $(\mathrm{H}+)$ in the cells results in their death [16]. Bleach, a bactericide, a fungicide tested in the laboratory according to the standard EN 13697 after a contact time of $15 \mathrm{mi}$ nutes. Used at a high concentration, bleach may attack the surface to which it has been applied and thus cause crevices favorable to the implantation of microorganisms.

The responses on the frequency of cleaning/disinfection obtained in our survey are similar to those obtained in the INCA survey carried out by [17] [18] in the survey on consumer practices and hygiene recommendations. In fact, 56\% and $64 \%$ of respondents said they cleaned their refrigerator at least once a quarter.

The sponge (cloths), squeegee and buckets are the cleaning tools most often used in both structures. Using the same sponge to clean both cold chain devices and other surfaces promotes the circulation of microorganisms in the structure. In addition, a frequently used and thus almost always wet sponge is therefore very loaded with microorganisms [19]. Sponge washing can therefore constitute a mode of contamination of cold chain devices [20] [21]. The use of squeegees and a hand brush, which are aggressive for surfaces, should be avoided as they may cause scratches and thus promote the retention of dirt and micro-organisms.

\section{Conclusion}

Food pathogens and opportunists can survive on the surfaces of cold chain equipment in butcher shops and therefore pose a risk of cross-contamination. Through our results, we have established that butcher's cold chain devices for food storage are not as sterile. Enterobacteriaceae as well as molds constitute the resident flora of the internal surfaces of the devices of the cold chain in our environment, hence the importance of the control of the operating temperature, regular effective cleaning/disinfection regimes which must be communicated butcher shops 
in order to ensure the quality and safety of the surfaces made available to the production function and the sale of foodstuffs.

\section{Acknowledgements}

Thanks to the School of Public Health of the University of Lubumbashi and to all the authors of this article who made a significant contribution in the design, implementation and/or analysis and interpretation of the data, elaboration of the article and critical review of its content

\section{Conflicts of Interest}

The authors declare no conflicts of interest.

\section{References}

[1] Sirsat, S.A., Kim, K., Gibson, K.E., Crandall, P.G., Ricke, S.C. and Neal, J.A. (2014) Tracking Microbial Contamination in Retail Environments Using Fluorescent Powder: A Retail Delicatessen Environment Example. Journal of Visualized Experiments, No. 85, 51402. https://doi.org/10.3791/51402 https://www.ncbi.nlm.nih.gov/pmc/articles/PMC4123823

[2] Mangen, M.-J.J., Bouwknegt, M., Friesema, I.H.M., Haagsma, J.A., Kortbeek, L.M., Tariq, L., et al. (2015) Cost-of-Illness and Disease Burden of Food-Related Pathogens in the Netherlands, 2011. International Journal of Food Microbiology, 196, 84-93. https://doi.org/10.1016/j.ijfoodmicro.2014.11.022

[3] Kilonzo-Nthenge, A., Chen, F.C. and Godwin, S.L. (2008) Occurrence of Listeria and Enterobacteriaceae in Domestic Refrigerators. Journal of Food Protection, 71, 608-612. https://doi.org/10.4315/0362-028X-71.3.608

[4] Mahajan, R., Garg, S. and Sharma, P.B. (2014) Global Food Safety: Determinants Are Codex Standards and WTO's SPS Food Safety Regulations. Journal of Advances in Management Research, 11, 176-191. https://doi.org/10.1108/JAMR-01-2013-0007

[5] Bendeddouche, B. and Bensid, A. (2009) Control of the Efficiency of Equipment Cleaning and Disinfection Operations in a Poultry Slaughterhouse in Algeria. European Journal of Scientific Research, 27, 181-187.

[6] Macias-Rodriguez, M.E., Navarro-Hidalgo, V., Linares-Morales, J.R., Olea-Rodriguez, M.A., Villarruel-López, A., Castro-Rosas, J., et al. (2013) Microbiological Safety of Domestic Refrigerators and the Dishcloths Used to Clean Them in Guadalajara, Jalisco, Mexico. Journal of Food Protection, 76, 984-990.

https://doi.org/10.4315/0362-028X.JFP-12-258

[7] Kampmann, Y., De Clerck, E., Kohn, S., Patchala, D.K., Langerock, R. and Kreyenschmidt, J. (2008) Study on the Antimicrobial Effect of Silver-Containing Inner Liners in Refrigerators. Journal of Applied Microbiology, 104, 1808-1814. https://doi.org/10.1111/j.1365-2672.2008.03727.x

[8] Omba, I.K., Koba, C.M., Ngongo, G.M. and Luboya, O.N. (2020) Quality Control of Juices Produced in Democratic Republic of Congo and Marketed in Lubumbashi. Food and Nutrition Sciences, 11, 255-261. https://doi.org/10.4236/fns.2020.114019

[9] Otu-Bassey, I.B., Ewaoche, I.S., Okon, F.B. and Ibor, U.A. (2017) Microbial Contamination of House Hold Refrigerators in Calabar Metropolis-Nigeria. American Journal of Epidemiology and Infectious Disease, 51, 1-7.

[10] Zickrick, K., Wittenberg, U. and Kiewel, S. (1995) Beitrag zum mikrobiellen Status der 
inneren Oberflächen und der Luft von Haushaltskühlschränken. Archiv fur Lebensmittelhygiene, 46, 91-94.

[11] Altunatmaz, S.S., Issa, G. and Aydin, A. (2012) Detection of Airborne Psychrotrophic Bacteria and Fungi in Food Storage Refrigerators. Brazilian Journal of Microbiology, 43, 1436-1443. https://doi.org/10.1590/S1517-83822012000400027

[12] Oluwafemi, F., Akpoguma, S., Oladiran, T. and Kolapo, A.L. (2015) Microbiological Quality of Household Refrigerators in Three Cities South-West of Nigeria. https://www.semanticscholar.org/paper/Microbiological-Quality-of-Household-Ref rigerators-Oluwafemi-Akpoguma/deb64f5b471e9053a4b4acec6783823b2849326e

[13] Marklinder, I.M., Lindblad, M., Eriksson, L.M., Finnson, A.M. and Lindqvist, R. (2004) Home Storage Temperatures and Consumer Handling of Refrigerated Foods in Sweden. Journal of Food Protection, 67, 2570-2577. https://doi.org/10.4315/0362-028X-67.11.2570

[14] WHO (2007) Guidelines for the Safe Preparation, Storage and Handling of Powdered Infant Formula.

[15] Garrido, V., García-Jalón, I. and Vitas, A.I. (2010) Temperature Distribution in Spanish Domestic Refrigerators and Its Effect on Listeria monocytogenes Growth in Sliced Ready-to-Eat Ham. Food Control, 21, 896-901. https://doi.org/10.1016/j.foodcont.2009.12.007

[16] Yang, H., Kendall, P.A., Medeiros, L. and Sofos, J.N. (2009) Inactivation of Listeria monocytogenes, Escherichia coli O157:H7, and Salmonella typhimurium with Compounds Available in Households. Journal of Food Protection, 72, 1201-1208. https://doi.org/10.4315/0362-028X-72.6.1201

[17] Bjornsdottir, K., Breidt, F. and McFeeters, R.F. (2006) Protective Effects of Organic Acids on Survival of Escherichia coli O157:H7 in Acidic Environments. Applied and Environmental Microbiology, 72, 660-664. https://doi.org/10.1128/AEM.72.1.660-664.2006

[18] Volatier, J.L. (2000) Individual and National INCA Survey on Food Consumption. Tec Doc, Paris.

[19] Lagendijk, E., Asséré, A., Derens, E. and Carpentier, B. (2010) Domestic Refrigeration: Survey of Consumer Practices and Hygiene Recommendations. Journal of Food Protection, 71, 1898-1904.

[20] Josephson, K.L., Rubino, J.R. and Pepper, I.L. (1997) Characterization and Quantification of Bacterial Pathogens and Indicator Organisms in Household Kitchens with and without the Use of a Disinfectant Cleaner. Journal of Applied Microbiology, 83, 737-750. https://doi.org/10.1046/j.1365-2672.1997.00308.x

[21] Mattick, K., Durham, K., Domingue, G., Jørgensen, F., Sen, M., Schaffner, D.W., et al. (2003) The Survival of Foodborne Pathogens during Domestic Washing-Up and Subsequent Transfer onto Washing-Up Sponges, Kitchen Surfaces and Food. International Journal of Food Microbiology, 85, 213-226.

https://doi.org/10.1016/S0168-1605(02)00510-X 